\title{
Z

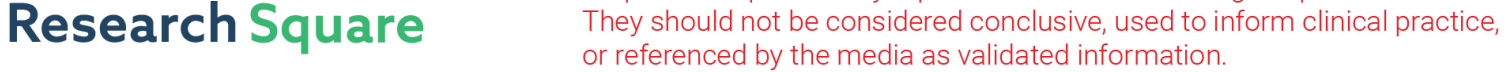 \\ Co-occurrence of Relapsing Polychondoritis and Autoimmune Thyroid Diseases
}

\section{Toshiki Nakajima}

Department of Clinical Immunology and Rheumatology, Tazuke Kofukai Research Institute, Kitano Hospital

\section{Hajime Yoshifuji}

Department of Rheumatology and Clinical Immunology, Kyoto University Graduate School of Medicine

\section{Yoshihisa Yamano}

Department of Rare Disease Research, Institute of Medical Science, St. Marianna University of Medicine

\section{Kimiko Yurugi}

Department of Transfusion Medicine and Cell Therapy, Kyoto University Hospital

\section{Yasuo Miura}

Department of Transfusion Medicine and Cell Therapy, Kyoto University Hospital

\section{Taira Maekawa}

Department of Transfusion Medicine and Cell Therapy, Kyoto University Hospital

\section{Tsuneyasu Yoshida}

Department of Rheumatology and Clinical Immunology, Kyoto University Graduate School of Medicine Hiroshi Handa

Division of Respiratory and Infectious Diseases, Department of Internal Medicine, St. Marianna University of Medicine

\section{Koichiro Ohmura}

Department of Rheumatology and Clinical Immunology, Kyoto University Graduate School of Medicine

\section{Tsuneyo Mimori}

Department of Rheumatology and Clinical Immunology, Kyoto University Graduate School of Medicine Chikashi Terao ( $\square$ chikashi.terao@riken.jp)

RIKEN: Rikagaku Kenkyujo https://orcid.org/0000-0002-6452-4095

\section{Research}

Keywords: Relapsing polychondritis, autoimmune thyroid disease, Human Leucocyte Antigen

Posted Date: October 1st, 2021

DOI: https://doi.org/10.21203/rs.3.rs-193156/v2 
License: (c) (i) This work is licensed under a Creative Commons Attribution 4.0 International License. Read Full License 


\section{Abstract}

Background: Relapsing polychondritis (RP) is a rare inflammatory disease characterized by recurrent inflammation and destruction of cartilageous tissues. RP has characteristics of autoimmune disease and some reports have noted co-occurrence with autoimmune thyroid disease (AITD), consisting of Graves' disease (GD) and Hashimoto thyroiditis (HT). However there have been no detailed studies on the cooccurrence of RP and AITD. In this study, we aimed to determine whether patients with RP tend to be complicated with AITD. We also analyzed clinical and genetic profiles of patients in whom these diseases co-occur.

Methods: We recruited 117 patients with RP and reviewed their medical records. Furthermore, we genotyped Human Leucocyte Antigen (HLA)-A, B Cw, DRB1, DQB1 and DPB1 alleles for 93 of the 117 patients. The prevalence of AITD among the patients with RP was compared with that among the general Japanese population. We also analyzed the clinical and genetic features of the patients with both RP and AITD.

Results: The prevalence of GD among the patients with RP was 4.3\% (5 among 117 patients), significantly higher than that among Japanese $(0.11 \%)\left(p=2.44 \times 10^{-7}\right.$, binomial test). RP patients with GD tended to have nasal involvement $(p=0.023)$ (odds ratio (OR) 2.58) and HLA-DPB1*02:02 $(p=0.035, O R$ 10.41). We did not find significant enrichment of HT in patients with RP.

Conclusions: Patients with RP appear to be at elevated risk of GD. Nasal involvement and HLADPB $1 * 02: 02$ may characterize the subset of RP patients with GD, which may guide attempts to characterize distinct subtype of RP for precision medicine.

\section{Background}

Relapsing polychondritis (RP) is a rare inflammatory disease characterized by recurrent inflammation and destruction of cartilaginous tissues, such as external ears, nose and airways. RP also affects joints, inner ears, eyes and large vessels. Patients with RP sometimes produce autoantibodies against collagen type II (1). Thus, RP has been regarded as an autoimmune disease.

While the causative factors associated with development of RP are not well known, genetic studies have provided supportive evidence of the nature of RP as an autoimmune disease. Firestein GS et al. reported the association of Human Leucocyte Antigen (HLA)- DR4 with Caucasian patients with RP (2). Our group previously reported that HLA class II loci are important for RP susceptibility in Japanese subjects as well (3). These results indicate that RP susceptibility is associated with HLA class II genes more than one ethnicity.

$\mathrm{RP}$ is reported to co-occur with other autoimmune diseases, including Beçhet disease (BD) (4), rheumatoid arthritis, systemic vasculitis, and autoimmune thyroid disease (AITD) (5). However, none of the associations with RP were supported by epidemiological or genetic studies using (relatively) large 
sample sizes, likely due to low prevalence of RP. For example, although BD in the setting of RP is famous as "MAGIC syndrome" (4), our previous study revealed that BD and RP did not have HLA susceptibility alleles in common with enough statistical power (3). Thus, whether the autoimmune diseases reported to co-occur with RP are actually more frequently observed in patients with RP due to an RP-related pathogenic mechanism, or whether these diseases co-occur by coincidence, is not known.

Through daily clinical practice with patients with RP, we noticed that patients with RP seemingly had high co-occurrence of AITD, consisting of Graves' disease (GD) and Hashimoto thyroiditis (HT). Moreover, the association of AITD with HLA has also reported (6) and this suggests that RP and AITD may have common genetic factors. In this study, we aimed to address whether AITD is significantly more prevalent among patients with RP. Furthermore, we tried to find the clinical and genetic features which characterize the co-occurrence of RP and AITD.

\section{Results}

\section{The prevalence of AITD in patients with RP}

We analyzed a total of 117 patients with RP whose clinical data were available. Their detailed characteristics are indicated in Table 1.

Table 1

Characteristics of the 117 patients with relapsing polychondritis

\begin{tabular}{|ll|}
\hline Sex (male/female) & $35 / 82$ \\
\hline Age (years old) & $54.3 \pm 15.4^{*}$ \\
\hline Age of onset (years old) & $43.2 \pm 16.6^{*}$ \\
\hline Complication of Graves' disease & $5 / 117(4.3 \%)$ \\
\hline Complication of Hashimoto's thyroiditis & $6 / 117(5.1 \%)$ \\
\hline Organ involvement & \\
\hline Auricular & $92 / 117(78.6 \%)$ \\
\hline Nasal & $56 / 117(47.9 \%)$ \\
\hline Tracheobronchial & $66 / 116(56.9 \%)$ \\
\hline Audio vestibular & $50 / 117(42.7 \%)$ \\
\hline Ophthalmic & $55 / 117(47.0 \%)$ \\
\hline Articular & $57 / 115(49.6 \%)$ \\
\hline$*$ : Average \pm standard deviation & \\
\hline
\end{tabular}


Among the 117 patients with RP, 5 (4.3\%) also carried a diagnosis of GD. The prevalence of GD among the patients with RP was significantly higher than that among the general population which was reported to be at most $0.11 \%(7)\left(p=2.44 \times 10^{-7}\right.$, Fig. 1). Six (5.1\%) were also diagnosed with HT. The prevalence of HT among the patients with RP was similar to that among the general population (4.6\%) (8) $(p=0.66$, Fig. 1).

\section{Clinical features of RP patients with AITD}

Next, we analyzed clinical features of the co-occurrence of RP and GD. All patients were female, which was not a significant difference from the male/female ratio of all RP patients $(p=0.32)$. The average age at RP onset was $49.2 \pm 10.9$ and $42.9 \pm 16.9$ in the RP patients with and without GD, respectively $(p=$ $0.28)$.

With respect to the organs involved by RP, all the RP patients with GD had auricular and nasal involvements and only one of the five RP patients with GD had audio vestibular and ophthalmic involvements. RP patients with GD tended to have nasal involvement at a higher rate than RP patients without GD (100\% vs $45.5 \%, \mathrm{p}=0.023$, OR 2.58, [95\% Cl 1.09 $\infty$ ], Table 2). We observed a trend of more organ involvements in the co-occurrence $(3.41 \pm 1.14$ vs $3.18 \pm 1.46)$, suggesting that the RP patients with GD may have more severe and widespread disease.

Table 2

Differences of organ involvement between patients with and without Graves' disease

\begin{tabular}{|c|c|c|c|c|}
\hline & $\begin{array}{l}\text { Patients with GD } \\
(\mathrm{N}=5)\end{array}$ & $\begin{array}{l}\text { Patients without GD } \\
(\mathrm{N}=112)\end{array}$ & P-value & $\begin{array}{l}\text { Odds ratio } \\
\text { [ } 95 \% \text { confidence interval] }\end{array}$ \\
\hline Auricular & $5 / 5(100 \%)$ & $87 / 112$ (77.7\%) & 0.58 & $\operatorname{lnf}[0.26 \sim \operatorname{lnf}]$ \\
\hline Nasal & $5 / 5(100 \%)$ & $51 / 112(45.5 \%)$ & 0.023 & $\operatorname{lnf}[1.09 \sim \operatorname{lnf}]$ \\
\hline Tracheobronchial & $3 / 5(60 \%)$ & $63 / 111(56.8 \%)$ & 1.00 & $1.14[0.17 \sim 9.52]$ \\
\hline Audio vestibular & $1 / 5(20 \%)$ & $49 / 112(43.8 \%)$ & 0.39 & $0.32[0.013 \sim 2.58]$ \\
\hline Ophthalmic & $1 / 5(20 \%)$ & $54 / 112(48.2 \%)$ & 0.37 & $0.27[0.011 \sim 2.16]$ \\
\hline Auricular & $2 / 5(40 \%)$ & $55 / 110(50.0 \%)$ & 1.00 & $0.67[0.080 \sim 4.46]$ \\
\hline \multicolumn{5}{|c|}{ Patients with GD tended to have nasal involvement compared with the patients without GD. } \\
\hline \multicolumn{5}{|c|}{ P-value was obtained by Fisher's exact test } \\
\hline GD: Graves' diseas & & & & \\
\hline
\end{tabular}


There were no clinical differences between the RP patients with HT and without HT (Supplementary Table S1).

\section{Associations between HLA alleles and co-occurrence of RP and AITD}

Because classical HLA alleles are reported to be associated with development of RP (2) (3) and AITD (6), associations between classical HLA alleles and co-occurrence of these diseases were addressed. As a result, the frequency of HLA-DPB1*02:02 tended to be higher in patients with co-occurrence of GD and RP (20\% vs 2.3\%, p = 0.035, OR 10.41 [95\% $\mathrm{Cl} 1.23 \sim 65.38$ ]) and none of the other HLA alleles (A, B, Cw, DRB1, and DQB1) showed even suggestive associations with AITD co-occurrence (Table 3). No HLA alleles were associated with the co-occurrence of HT (Supplementary Table S2). There were no distinct clinical features of the RP patients with both GD and HLA-DPB1*02:02. The average age at onset of RP was $51.0 \pm 5.66$ among the RP patients with both GD and HLA-DPB $1 * 02: 02$ and this was slightly higher than that of the RP patients without GD $(42.4 \pm 16.8, p=0.24)$. 
Table 3

Human Leucocyte Antigen (HLA) alleles in patients with RP with and without GD.

$\begin{array}{llll}\text { Patients with } & \text { Patients without } & \text { P-value }^{*} & \text { Odds ratio } \\ \text { GD }(\mathrm{N}=5) & \mathrm{GD}(\mathrm{N}=88) & & \text { [95\% confidence interval] }\end{array}$

HLA-A

\begin{tabular}{lllll}
$02: 01$ & $2(20 \%)$ & $19(10.8 \%)$ & 0.31 & $2.01[0.29 \sim 9.78]$ \\
\hline $02: 06$ & $1(10 \%)$ & $19(10.8 \%)$ & 1.00 & $0.92[0.040 \sim 6.46]$ \\
\hline $02: 07^{* *}$ & $1(10 \%)$ & $4(2.3 \%)$ & 0.24 & $4.70[0.18 \sim 40.87]$ \\
\hline $11: 01$ & $1(10 \%)$ & $27(15.3 \%)$ & 1.00 & $0.61[0.027 \sim 4.12]$ \\
\hline $24: 02$ & $3(30 \%)$ & $55(31.3 \%)$ & 1.00 & $0.94[0.20 \sim 3.67]$ \\
\hline $26: 01$ & $0(0 \%)$ & $12(6.8 \%)$ & 1.00 & $0[0.00 \sim 6.01]$ \\
\hline $26: 03$ & $1(10 \%)$ & $4(2.3 \%)$ & 0.24 & $4.70[0.18 \sim 40.87]$ \\
\hline $31: 01$ & $2(20 \%)$ & $19(10.8 \%)$ & 0.31 & $2.06[0.29 \sim 9.78]$ \\
\hline $33: 03$ & $0(0 \%)$ & $14(8.0 \%)$ & 1.00 & $0[0.00 \sim 5.97]$
\end{tabular}

HLA-B

\begin{tabular}{lllll}
$07: 02$ & $0(0 \%)$ & $10(5.7 \%)$ & 1.00 & $0[0.00 \sim 7.14]$ \\
\hline $15: 01$ & $2(20 \%)$ & $18(10.2 \%)$ & 0.30 & $2.18[0.31 \sim 10.48]$ \\
\hline $35: 01 *$ & $1(10 \%)$ & $18(10.2 \%)$ & 1.00 & $0.98[0.043 \sim 6.93]$ \\
\hline $39: 01$ & $0(0 \%)$ & $7(4.0 \%)$ & 1.00 & $0[0.00 \sim 11.88]$ \\
\hline $40: 01$ & $0(0 \%)$ & $11(6.3 \%)$ & 1.00 & $0[0.00 \sim 6.51]$ \\
\hline $40: 02$ & $1(10 \%)$ & $12(6.8 \%)$ & 0.52 & $1.51[0.065 \sim 11.84]$ \\
$40: 06$ & $0(0 \%)$ & $4(2.3 \%)$ & 1.00 & $0[0.00 \sim 21.06]$ \\
\hline $44: 03$ & $0(0 \%)$ & $10(5.7 \%)$ & 1.00 & $0[0.00 \sim 7.14]$
\end{tabular}

The frequency of HLA-DPB $1 * 02: 02$ was higher in the RP patients with GD than in the patients without GD.

Alleles of which frequencies in general Japanese were over $2 \%$, alleles found among the RP patients with Graves' disease and alleles which have been reported to be associated with autoimmune thyroiditis, relapsing polychondritis and Bechet disease were listed.

P-value was obtained by Fisher's exact test

GD: Graves' disease, Inf: infinity

*: risk allele for Graves' disease, $\star *$ : risk allele for Hashimoto thyroiditis, $* \star *$ : risk allele for relapsing polychondritis, †: risk allele for Bechet disease 


\begin{tabular}{|c|c|c|c|c|}
\hline & $\begin{array}{l}\text { Patients with } \\
\text { GD }(N=5)\end{array}$ & $\begin{array}{l}\text { Patients without } \\
\text { GD }(\mathrm{N}=88)\end{array}$ & P-value ${ }^{*}$ & $\begin{array}{l}\text { Odds ratio } \\
\text { [95\% confidence interval] }\end{array}$ \\
\hline $46: 01^{*}$ & $1(10 \%)$ & $4(2.3 \%)$ & 0.24 & $4.70[0.18 \sim 40.87]$ \\
\hline 48:01 & $0(0 \%)$ & $4(2.3 \%)$ & 1.00 & $0[0.00 \sim 21.06]$ \\
\hline $51: 01^{\dagger}$ & $2(20 \%)$ & $14(8.0 \%)$ & 0.21 & $2.87[0.40 \sim 14.55]$ \\
\hline $52: 01$ & $1(10 \%)$ & $16(9.1 \%)$ & 1.00 & $1.11[0.049 \sim 8.07]$ \\
\hline $54: 01$ & $1(10 \%)$ & $18(10.2 \%)$ & 1.00 & $1.00[0.043 \sim 6.93]$ \\
\hline $55: 02$ & $0(0 \%)$ & $6(3.4 \%)$ & 1.00 & $0.98[0.00 \sim 15.36]$ \\
\hline 59:01 & $0 / 10(0 \%)$ & $5 / 176(2.8 \%)$ & 1.00 & $0[0.00 \sim 17.83]$ \\
\hline $67: 01^{\star \star \star}$ & $1 / 10(10 \%)$ & $5 / 176(2.8 \%)$ & 0.29 & $3.75[0.15 \sim 36.33]$ \\
\hline \multicolumn{5}{|l|}{ HLA-Cw } \\
\hline 01:02 & $2(20 \%)$ & 33 (18.8\%) & 1.00 & $1.08[0.16 \sim 5.03]$ \\
\hline 03:03 & $3(30 \%)$ & $26(14.8 \%)$ & 0.19 & $2.46[0.52 \sim 9.91]$ \\
\hline 03:04 & $1(10 \%)$ & $22(12.5 \%)$ & 1.00 & $0.78[0.035 \sim 5.36]$ \\
\hline 04:01 & $0(10 \%)$ & $9(5.1 \%)$ & 1.00 & $0[0.00 \sim 8.21]$ \\
\hline 07:02 & $1(10 \%)$ & $28(15.9 \%)$ & 1.00 & $0.59[0.026 \sim 3.94]$ \\
\hline 08:01 & $0(0 \%)$ & $10(5.7 \%)$ & 1.00 & $0[0.00 \sim 7.14]$ \\
\hline $12: 02$ & $1(10 \%)$ & $17(9.7 \%)$ & 1.00 & $1.04[0.046 \sim 7.46]$ \\
\hline 14:02 & $2(20 \%)$ & $11(6.3 \%)$ & 0.15 & $3.71[0.51 \sim 20.24]$ \\
\hline 14:03 & $0(0 \%)$ & $10(5.7 \%)$ & 1.00 & $0[0.00 \sim 7.14]$ \\
\hline 15:02 & $0(0 \%)$ & $4(2.3 \%)$ & 1.00 & $0[0.00 \sim 21.06]$ \\
\hline \multicolumn{5}{|c|}{ HLA-DRB1 } \\
\hline \multicolumn{5}{|c|}{$\begin{array}{l}\text { The frequency of HLA-DPB } 1 * 02: 02 \text { was higher in the RP patients with GD than in the patients without } \\
\text { GD. }\end{array}$} \\
\hline \multicolumn{5}{|c|}{$\begin{array}{l}\text { Alleles of which frequencies in general Japanese were over } 2 \% \text {, alleles found among the RP patients } \\
\text { with Graves' disease and alleles which have been reported to be associated with autoimmune } \\
\text { thyroiditis, relapsing polychondritis and Bechet disease were listed. }\end{array}$} \\
\hline \multicolumn{5}{|c|}{ P-value was obtained by Fisher's exact test } \\
\hline \multicolumn{5}{|c|}{ GD: Graves' disease, Inf: infinity } \\
\hline $\begin{array}{l}\text { *: risk alle } \\
\text { polychonc }\end{array}$ & $\begin{array}{l}\text { r Graves' disea } \\
s, t \text { : risk allele f }\end{array}$ & $\begin{array}{l}* \text { risk allele for } \mathrm{Ha} \\
\text { chet disease }\end{array}$ & to thyro & $\star \star \star$ : risk allele for relapsing \\
\hline
\end{tabular}




\begin{tabular}{|c|c|c|c|c|}
\hline & $\begin{array}{l}\text { Patients with } \\
\mathrm{GD}(\mathrm{N}=5)\end{array}$ & $\begin{array}{l}\text { Patients without } \\
\text { GD }(\mathrm{N}=\mathbf{8 8})\end{array}$ & P-value ${ }^{*}$ & $\begin{array}{l}\text { Odds ratio } \\
\text { [95\% confidence interval] }\end{array}$ \\
\hline 01:01 & $0(0 \%)$ & $9(5.1 \%)$ & 1.00 & $0[0.00 \sim 8.21]$ \\
\hline 04:03 & $0(0 \%)$ & $6(3.4 \%)$ & 1.00 & $0[0.00 \sim 15.36]$ \\
\hline 04:05 & $0(0 \%)$ & 31 (17.6\%) & 0.22 & $0[0.0 \sim 2.14]$ \\
\hline 04:06 & $0(0 \%)$ & $9(5.1 \%)$ & 1.00 & $0[0.00 \sim 8.21]$ \\
\hline 04:07 & $1(10 \%)$ & $2(1.1 \%)$ & 0.15 & 9.38 [0.30 129.97] \\
\hline 04:10 & $0(0 \%)$ & $3(1.7 \%)$ & 1.00 & $0[0.00 \sim 32.00]$ \\
\hline 08:02 & $1(10 \%)$ & $7(4.0 \%)$ & 0.36 & $2.66[0.11 \sim 20.53]$ \\
\hline 08:03 & $0(0 \%)$ & $11(6.3 \%)$ & 1.00 & $0[0.00 \sim 6.51]$ \\
\hline 09:01 & $2(20 \%)$ & 22 (12.5\%) & 0.62 & $1.74[0.25 \sim 8.14]$ \\
\hline 11:01 & $0(0 \%)$ & $5(2.8 \%)$ & 1.00 & $0[0.00 \sim 17.83]$ \\
\hline $12: 01$ & $2(20 \%)$ & $6(3.4 \%)$ & 0.061 & $6.92[0.89 \sim 38.52]$ \\
\hline 13:02 & $0(0 \%)$ & $9(5.1 \%)$ & 1.00 & $0[0.00 \sim 8.21]$ \\
\hline $14: 03^{*}$ & $0(0 \%)$ & $2(1.1 \%)$ & 1.00 & $0[0.00 \sim 63.42]$ \\
\hline $14: 05$ & $1(10 \%)$ & $0(0 \%)$ & 0.054 & $\operatorname{Inf}[0.93 \sim \operatorname{lnf}]$ \\
\hline $14: 54$ & $1(10 \%)$ & $8(4.5 \%)$ & 0.40 & $2.32[0.096 \sim 18.37]$ \\
\hline 15:01 & $1(10 \%)$ & 15 (8.5\%) & 0.60 & $1.19[0.052 \sim 8.78]$ \\
\hline 15:02 & $0(0 \%)$ & $16(9.1 \%)$ & 1.00 & $0[0.00 \sim 5.00]$ \\
\hline $16: 02^{\star \star \star}$ & $1(10 \%)$ & $5(2.8 \%)$ & 0.29 & $3.75[0.15 \sim 36.33]$ \\
\hline \multicolumn{5}{|c|}{ HLA-DQB1 } \\
\hline 03:01 & $2(20 \%)$ & $16(9.1 \%)$ & 0.25 & $2.48[0.35 \sim 12.21]$ \\
\hline \multicolumn{5}{|c|}{$\begin{array}{l}\text { The frequency of HLA-DPB } 1 * 02: 02 \text { was higher in the RP patients with GD than in the patients without } \\
\text { GD. }\end{array}$} \\
\hline \multicolumn{5}{|c|}{$\begin{array}{l}\text { Alleles of which frequencies in general Japanese were over } 2 \% \text {, alleles found among the RP patients } \\
\text { with Graves' disease and alleles which have been reported to be associated with autoimmune } \\
\text { thyroiditis, relapsing polychondritis and Bechet disease were listed. }\end{array}$} \\
\hline \multicolumn{5}{|c|}{ P-value was obtained by Fisher's exact test } \\
\hline \multicolumn{5}{|c|}{ GD: Graves' disease, Inf: infinity } \\
\hline $\begin{array}{l}\text { *: risk alle } \\
\text { polychonc }\end{array}$ & $\begin{array}{l}\text { or Graves' disea } \\
\text {, t: risk allele f }\end{array}$ & $\begin{array}{l}: \text { risk allele for } \mathrm{Ha} \\
\text { chet disease }\end{array}$ & to thyroi & $\star \star \star *$ risk allele for relapsing \\
\hline
\end{tabular}




\begin{tabular}{|c|c|c|c|c|}
\hline & $\begin{array}{l}\text { Patients with } \\
\text { GD }(N=5)\end{array}$ & $\begin{array}{l}\text { Patients without } \\
\mathrm{GD}(\mathrm{N}=88)\end{array}$ & P-value ${ }^{*}$ & $\begin{array}{l}\text { Odds ratio } \\
\text { [95\% confidence interval] }\end{array}$ \\
\hline 03:02 & $1(10 \%)$ & $23(13.1 \%)$ & 1.00 & $0.74[0.033 \sim 5.06]$ \\
\hline 03:03 & $3(30 \%)$ & $26(14.8 \%)$ & 0.19 & $2.46[0.52 \sim 9.91]$ \\
\hline 04:01 & $0(0 \%)$ & $31(17.6 \%)$ & 0.22 & $0[0.00 \sim 2.14]$ \\
\hline 04:02 & $1(10 \%)$ & $5(2.8 \%)$ & 0.29 & $3.75[0.15 \sim 36.33]$ \\
\hline 05:01 & $0(0 \%)$ & $9(5.1 \%)$ & 1.00 & $0[0.00 \sim 8.21]$ \\
\hline $05: 02 * \star \star$ & $1(10 \%)$ & $12(6.8 \%)$ & 0.52 & $1.51[0.065 \sim 11.85]$ \\
\hline 05:03 & $1(10 \%)$ & $1(0.057 \%)$ & 0.10 & $18.49[0.46 \sim 751.60]$ \\
\hline 06:01 & $0(0 \%)$ & $27(15.3 \%)$ & 0.36 & $0[0.00 \sim 2.56]$ \\
\hline $06: 02$ & $1(10 \%)$ & $15(8.5 \%)$ & 0.60 & $1.19[0.052 \sim 8.78]$ \\
\hline 06:04 & $0(0 \%)$ & $8(4.5 \%)$ & 1.00 & $0[0.00 \sim 9.71]$ \\
\hline \multicolumn{5}{|c|}{ HLA-DPB1 } \\
\hline 02:01 & $1(10 \%)$ & $46(26.1 \%)$ & 0.46 & $0.32[0.014 \sim 2.07]$ \\
\hline 02:02 & $2(20 \%)$ & $4(2.3 \%)$ & 0.035 & $10.41[1.23 \sim 65.38]$ \\
\hline 03:01 & $0(0 \%)$ & $5(2.8 \%)$ & 1.00 & $0[0.00 \sim 17.83]$ \\
\hline 04:01 & $0(0 \%)$ & $9(5.1 \%)$ & 1.00 & $0[0.00 \sim 8.21]$ \\
\hline 04:02 & $0(0 \%)$ & $9(5.1 \%)$ & 1.00 & $0[0.00 \sim 8.21]$ \\
\hline 05:01* & $5(50 \%)$ & $83(47.2 \%)$ & 1.00 & $1.12[0.31 \sim 4.05]$ \\
\hline 09:01 & $1(10 \%)$ & $11(6.3 \%)$ & 0.50 & $1.66[0.071 \sim 13.38]$ \\
\hline 13:01 & $1(10 \%)$ & $3(1.7 \%)$ & 0.20 & $6.27[0.22 \sim 63.23]$ \\
\hline \multicolumn{5}{|c|}{$\begin{array}{l}\text { The frequency of HLA-DPB } 1 * 02: 02 \text { was higher in the RP patients with GD than in the patients without } \\
\text { GD. }\end{array}$} \\
\hline \multicolumn{5}{|c|}{$\begin{array}{l}\text { Alleles of which frequencies in general Japanese were over } 2 \% \text {, alleles found among the RP patients } \\
\text { with Graves' disease and alleles which have been reported to be associated with autoimmune } \\
\text { thyroiditis, relapsing polychondritis and Bechet disease were listed. }\end{array}$} \\
\hline \multicolumn{5}{|c|}{ P-value was obtained by Fisher's exact test } \\
\hline \multicolumn{5}{|c|}{ GD: Graves' disease, Inf: infinity } \\
\hline \multicolumn{5}{|c|}{$\begin{array}{l}\text { *: risk allele for Graves' disease, } * * \text { : risk allele for Hashimoto thyroiditis, } * * * \text { : risk allele for relapsing } \\
\text { polychondritis, } t: \text { risk allele for Bechet disease }\end{array}$} \\
\hline
\end{tabular}


We analyzed for associations between RP or GD susceptibility alleles and their co-occurrence. Lang et al. reported that HLA-DR4 is associated with RP development (2). Our previous report showed that HLA$B * 67: 01, H L A-D R B 1 * 16: 02$ and HLA-DQB1*05:02 are associated with development of RP (3). However, these alleles did not show associations with co-occurrence of GD in the patients with RP in this study (Supplementary Table S2). While HLA-B*35:01, $B * 46: 01$, DRB1*14:03 and DPB $1{ }^{*} 05: 01$ are risk alleles for GD (6), we found no associations between these alleles and GD co-occurrence in RP (HLA-B*46:01 showed a trend, Table 3).

Because our previous report showed serine at AA position 57 and histidine at AA position126 in HLADQB1 are associated with RP (3), finally we examined whether these AA associated with GD development in the patients with RP. One of RP patients with GD and 12 of RP patients without GD had this combination of AA ( $p=0.54)$ (OR 1.57 [95\% Cl $0.60 ~ 13.37])$.

\section{Discussion}

This study showed for the first time that patients with RP are more likely to be diagnosed with GD than general population in Japan. Although AITD has been reported to co-occur with RP in the previous literatures using a limited sample size, this co-occurrence has not been statistically shown. The data of the 117 subjects with RP, comprising more than $20 \%$ of all subjects with this diagnosis alive in Japan, enabled us to analyze the co-occurrence in a statistically robust manner. While, beyond nasal involvement by RP, we did not show common clinical features in patients with GD and RP, increasing samples size may reveal additional commonalities in auto-immune phenotype.

Although there was no national surveillance of AITD in Japanese, Akamizu et al. estimated the prevalence of GD among Japanese to be $0.073 \sim 0.11 \%$ based on the data of Japanese outpatient clinics (7). We took the conservative way and adopted the maximum number of that report, $0.11 \%$, as the prevalence of GD among general population in order to avoid false positive. To the contrary, there was no estimated prevalence of HT among Japanese, we selected the regional survey carried out in Hisayama (8), which was famous for epidemiological survey of cardiovascular disease et al. (9).

We also showed that HLA-DPB $1 * 02: 02$ was suggestively associated with the co-occurrence of RP and GD. Interestingly, HLA-DPB $1 * 02: 02$ had been reported to be associated with the mild phenotype of GD (10). The symptom of GD among the patients with RP may be mild and this may lead to overlooking of GD among the patients with RP. Clinicians are encouraged to be vigilant for GD co-occurring among their patients with RP.

Recently, we have reported the frequent co-occurrence of Takayasu arteritis and ulcerative colitis, one of inflammatory bowel diseases (IBD), driven by HLA-B*52:01 (11). We also reported that a treatment for IBD, ustekinumab, could be applied to the treatment for Takayasu arteritis (12). This may indicate that if one disease commonly co-occurs with another disease and these two diseases have a common genetic background, a treatment for one disease could potentially be applicable to the other. This hypothesis could be applied to RP and AITD. In fact, glucocorticoids are the mainstay of the treatment for RP (13) 
and Graves' orbitopathy (14), which is an eye involvement of GD. Further study is necessary to analyze common basic mechanisms underlying these two diseases, which may lead to novel treatment options potentially useful for both.

There are some limitations to our study. First, this study is a retrospective study and thyroid function tests are available in a limited number of patients with RP. This prevents us from analyzing in detail relationship between GD and RP susceptibility or its genetic components (such as whether RP patients high higher/lower thyroid function in general). Second, the number of RP patients with AITD was so small that we may fail to find important clinical or genetic features of the RP patients with AITD. Indeed, the statistical power of HLA-DPB $1 * 02: 02$ to obtain $p$-value less than 0.05 in this study was only 0.01 . More patients with RP should be prospectively recruited for further studies on the association of RP and AITD to identify important clinical and genetic features characterizing the co-occurrence.

\section{Conclusions}

This study is the first report that patients with RP have significantly higher prevalence of GD than general Japanese. The RP patients with GD may be characterized by the nasal involvement and inheritance of HLA-DPB1*02:02.

\section{Methods}

\section{Patients}

We recruited 124 patients with RP from Kyoto University Hospital, St Marianna University Hospital and the Japanese Committee of patients with RP, the name of which is HORP (Helpful/Harmonious/Hopeful Organization for Relapsing Polychondritis). All the patients with RP fulfilled the diagnostic criteria of McAdams (15) or Damiani (16). Seven of 124 patients were excluded from this study because of lack of clinical information. Patients with RP complicated with AITD were fulfilled guidelines of the Japan Thyroid Association for the diagnosis of GD and HT (http://www.japanthyroid.jp/en/guidelines.html) or diagnosed as AITD by the specialists of thyroid diseases based on clinical information. Written informed consent was obtained from each participant. This study was approved by the Kyoto University Graduate School and Faculty of Medicine, Ethics Committee and the ethics committee of St Marianna University School of Medicine and carried out in accordance with the Declaration of Helsinki.

\section{Data collection of patients}

We performed a retrospective chart review of 117 patients with RP in order to determine their clinical features including sex, age at this study, age at RP onset, organ involvements and co-occurrence of AITD. Among the many potential organ involvements of RP, we scored presence or absence of involvement of six sites, namely auricular, nasal, tracheobronchial, audio-vestibular, ophthalmic and articular involvements, which are listed in the diagnostic criteria of McAdams (15). 


\section{HLA genotyping and analysis}

We obtained blood cells or cells of buccal mucosa from 93 out of the 117 patients with RP for the genotyping of HLA. The WAKFlow system (Wakunaga) was used for genotyping of the classical HLA alleles in the six loci, namely, HLA-A, B, Cw, DRB1, DQB1 and DPB1, in the Department of Transfusion Medicine and Cell Therapy, Kyoto University Hospital. In order to obtain the data of amino acid (AA) position of HLA, we referred to the data of IPD-IMGT/HLA (https://www.ebi.ac.uk/ipd/imgt/hla/).

\section{Prevalence rate of AITD of general Japanese}

Since there has been no national surveillance of the prevalence of AITD in Japan, we used the estimated Japanese prevalence of GD by Akamizu et al. (7) and regional survey of prevalence of HT in Hisayama (8) as prevalence of AITD of general population.

\section{Statistical analysis}

Prevalence of diseases were compared with using binomial test, categorical variables were compared with using Fisher's exact test and continuous variables were compared with using Welch's $t$ test. P-values less than 0.05 after Bonferroni's correction were defined as statistically significant and uncorrected $p$ values are indicated in the main text, figure and tables. In the analysis of HLA, we selected alleles with frequencies of more than $2 \%$ in Japanese subjects according to the data of HLA Laboratory (http://hla.or.jp/), alleles which were found in the RP patients with AITD or alleles which are the risk alleles for RP, AITD and Beçhet disease. R 3.62 with packages "exact2x2" and "epi.R" was used for data analysis.

\section{Abbreviations}

RP: relapsing polychondritis, HLA: Human Leucocyte Antigen, BD: Beçhet disease, AITD: autoimmune thyroid disease, GD: Graves' disease, HT: Hashimoto thyroiditis, HORP: Helpful/Harmonious/Hopeful Organization for Relapsing Polychondritis, AA: amino acid, OR: odds ratio, $\mathrm{Cl}$ : confidence interval

\section{Declarations}

\section{Ethics approval and consent to participate}

This study was approved by the Kyoto University Graduate School and Faculty of Medicine, Ethics Committee, and the ethics committee of St Marianna University School of Medicine. All participants provided written informed consent.

\section{Consent for publication}

Written consent for publication was obtained from all the participants in this study. 
Availability of data and materials

The datasets used and/or analyzed during the current study are available from the corresponding author on reasonable request.

\section{Competing interests}

The authors have declared no conflicts of interest.

\section{Funding}

No founding was received for this study.

\section{Authors' contributions}

TN, HY and CT conceptualized and designed the study. TN, HY, YY, KY, YM, TM, TY, HH, KO, TM and CT collected clinical data. TN, HY, YY, KY, YM, TM, TY, HH, KO, TM and CT checked the quality of the data. TN and $C T$ analyzed the data in the study. TN and CT composed the original draft. HY, YY, KY, YM, TM, TY, $\mathrm{HH}, \mathrm{KO}, \mathrm{TM}$ and $\mathrm{CT}$ critically reviewed the manuscript. CT had leadership roles in the research. All authors read and approved the final manuscript.

\section{Acknowledgements}

We deeply thank Dr. Nicholas Parrish for critically reviewing and editing the manuscript.

We thank the patients' organization Helping, Harmonious and Hopeful Organization for Relapsing Polychondritis (HORP), Mr Katsutoshi Nagamatsu and Ms. Shiho Kato for their kind assistance. This study was not supported by specific funding sources.

\section{References}

1. Foidart JM, Abe S, Martin GR, Zizic TM, Barnett EV, Lawley TJ, et al. Antibodies to type Il collagen in relapsing polychondritis. N Engl J Med. 1978; 299: 1203-7.

2. Lang B, Rothenfusser A, Lanchbury JS, Rauh G, Breedveld FC, Urlacher A, et al. Susceptibility to relapsing polychondritis is associated with HLA-DR4. Arthritis Rheum. 1993; 36: 660-4.

3. Terao C, Yoshifuji H, Yamano Y, Kojima H, Yurugi K, Miura Y, et al. Genotyping of relapsing polychondritis identified novel susceptibility HLA alleles and distinct genetic characteristics from other rheumatic diseases. Rheumatology. 2016; 55: 1686-92.

4. Firestein GS, Gruber HE, Weisman MH, Zvaifler NJ, Barber J, O'Duffy JD. Mouth and genital ulcers with inflamed cartilage: MAGIC syndrome. Five patients with features of relapsing polychondritis and Behçet's disease. Am J Med. 1985; 79: 65-72.

5. Lekpa FK, Chevalier X. Refractory relapsing polychondritis: challenges and solutions. Open Access Rheumatol. 2018; 10: 1-11. 
6. Ueda S, Oryoji D, Yamamoto K, Noh JY, Okamura K, Noda M, et al. Identification of independent susceptible and protective HLA alleles in Japanese autoimmune thyroid disease and their epistasis. J Clin Endocrinol Metab. 2014; 99: E379-83.

7. Akamizu T, Nakamura Y, Tamaoki A, Inaba Y, Amino N, Seino Y. Prevalence and clinico-epidemiology of familial Graves' disease in Japan based on nationwide epidemiologic survey in 2001. Endocr J. 2003; 50: 429-36.

8. Okamura K, Nakashima T, Ueda K, Inoue K, Omae T, Fijishima M. Thyroid disorders in the general population of Hisayama Japan, with special reference to prevalence and sex differences. Int $J$ Epidemiol. 1987; 16: 545-9.

9. Ninomiya T. Japanese Legacy Cohort Studies: The Hisayama Study. J Epidemiol. 2018; 28: 444-451.

10. Takahashi M, Yasunami M, Kubota S, Tamai H, Kimura A. HLA-DPB $1 * 0202$ is associated with a predictor of good prognosis of Graves' disease in the Japanese. Hum Immunol. 2006; 67: 47-52.

11. Terao C, Matsumura T, Yoshifuji H, Kirino Y, Maejima Y, Nakaoka Y, et al. Takayasu arteritis and ulcerative colitis: high rate of co-occurrence and genetic overlap. Arthritis Rheumatol. 2015; 67: 222632.

12. Terao C, Yoshifuji H, Nakajima T, Yukawa N, Matsuda F, Mimori T. Ustekinumab as a therapeutic option for Takayasu arteritis: from genetic findings to clinical application. Scand J Rheumatol. 2016; 45: 80-82.

13. Longo L, Greco A, Rea A, Lo Vasco VR, De Virgilio A, De Vincentiis M. Relapsing polychondritis: A clinical update. Autoimmun Rev. 2016;15(6):539-43.

14. Xu N, Cui Y, Xie T, Zheng M. Comparative Efficacy of Medical Treatments for Thyroid Eye Disease: A Network Meta-Analysis. J Ophthalmol. 2018; 2018: 7184163.

15. McAdam LP, O'Hanlan MA, Bluestone R, Pearson CM. Relapsing polychondritis: prospective study of 23 patients and a review of the literature. Medicine (Baltimore). 1976; 55: 193-215.

16. Damiani JM, Levine HL. Relapsing polychondritis-report of ten cases. Laryngoscope. 1979; 89: 92946.

\section{Figures}




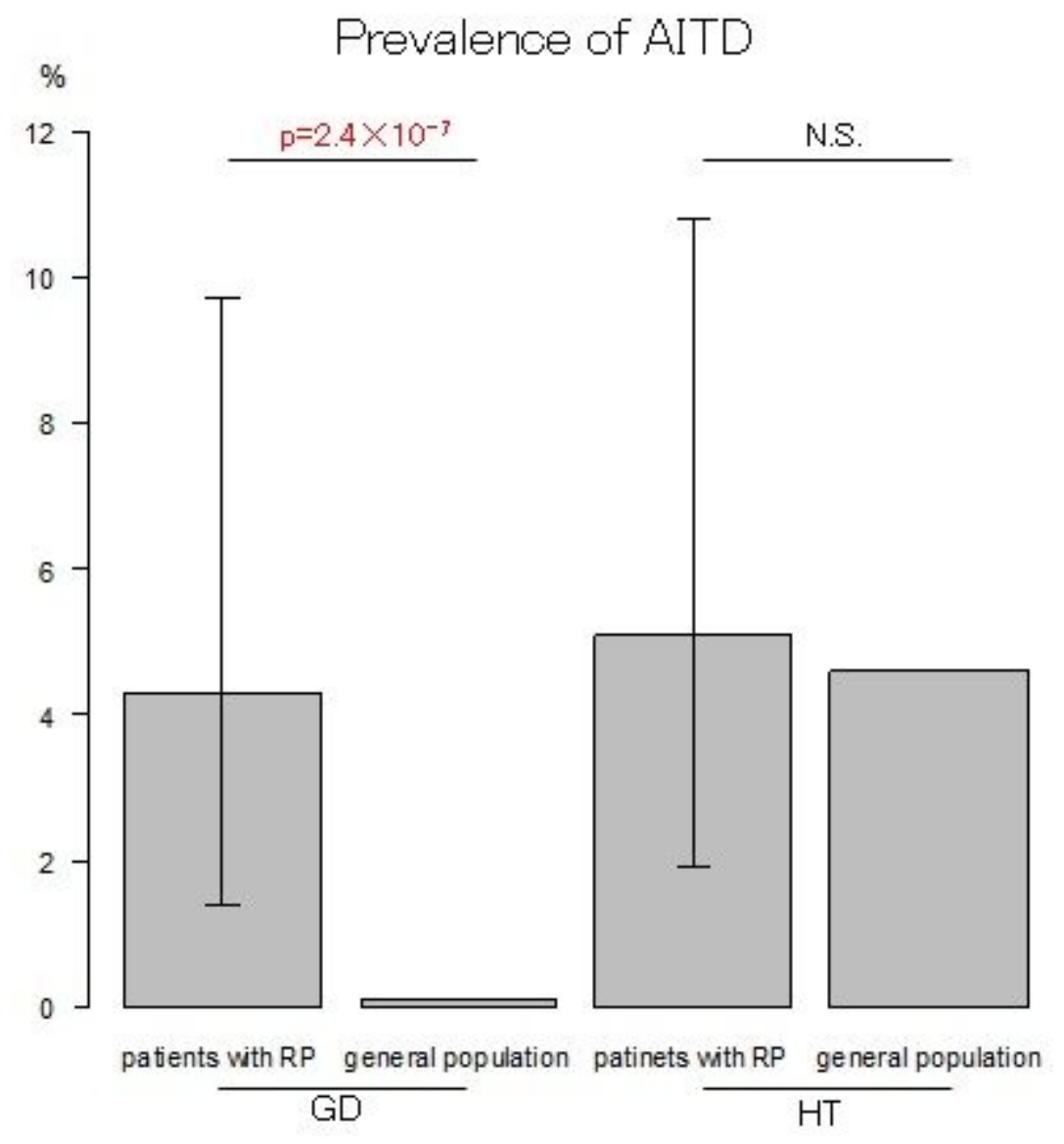

\section{Figure 1}

High co-occurrence rate of Graves' disease in patients with RP. The prevalence of AITD in the patients with RP is compared with that in the general population. Bars indicate $95 \%$ confidence intervals. AITD: autoimmune thyroid disease, RP: relapsing polychondritis, GD: Graves' disease, HT: Hashimoto thyroiditis, NS: not significant

\section{Supplementary Files}

This is a list of supplementary files associated with this preprint. Click to download.

- Supplementaryfile.docx 